\title{
PERANCANGAN CONTENT MANAGEMENT SYSTEM PROGRAM STUDI UNIVERSITAS DHYANA PURA MENGGUNAKAN METODE TCSD
}

\author{
Ni Putu Trisna Padmawati ${ }^{1)}$ Gerson Feoh ${ }^{2)}$ Putu Wida Gunawan ${ }^{3)}$ \\ Program Studi Teknik Informatika ${ }^{1)}{ }^{2)}$ )
}

Fakultas Ilmu Kesehatan Sains dan Teknologi, Universitas Dhyana Pura, Badung, Bali ${ }^{12)}$ 2) $^{3)}$ trisnapadma50@gmail.com ${ }^{1)}$ gerson.feoh@undhirabali.ac.id ${ }^{2)}$ putuwida@undhirabali.ac.id ${ }^{3)}$

\begin{abstract}
Dhyana Pura University is one of the Universities in Bali, which has 2 faculties and consists of 14 courses. At Dhyana University Pura already has a website that is used to provide information to students and the general public. However, in every study program Dhyana Pura University does not have standardization of Content Management System for study program information system. One of the steps that can be taken is to design the content management system of study program to standardize every website of study program of Dhyana Pura University.

Task Centered System Design method is a method in Human Computer Interaction (HCI) that is used to identify user needs and task needs. Where identification results are used as the basis of interface improvements supported by direct observation.

Testing this system using Black Box method and it can be concluded that the content management system was successfully designed and implemented. So from the test results, the purpose of making this system has been achieved where the user task needs have been in accordance with the task and user type on the content management system of the study program of Dhyana Pura University.
\end{abstract}

Keywords: Dhyana Pura University, Content Management System, Task Centered System Design, Black Boxes.

\begin{abstract}
ABSTRAK
Universitas Dhyana Pura adalah salah satu Universitas di Bali, yang mempunyai 2 fakultas dan terdiri dari 14 program studi. Di Universitas Dhyana Pura sudah mempunyai website yang digunakan untuk memberikan informasi kepada mahasiswa dan masyarakat umum. Akan tetapi di setiap program studi Universitas Dhyana Pura belum memiliki standardisasi Content Management System untuk system informasi program studi. Salah satu langkah yang bisa ditempuh adalah dengan merancang content management system program studi untuk menstandardisasikan setiap website program studi Universitas Dhyana Pura.

Metode Task Centered System Design adalah sebuah metode dalam Human Computer Interaction (HCI) yang digunakan untuk menegidentifikasikan kebutuhan user dan kebutuhan task. Dimana hasil identifikasi digunakan sebagai dasar perbaikan interface yang didukung dengan observasi langsung.

Pengujian system ini menggunakan metode Black Box dan dapat disimpulkan bahwa content management system ini berhasil dirancang dan diimplementasikan. Sehingga dari hasil pengujian, tujuan dari pembuatan system ini telah tercapai dimana kebutuhan task pengguna telah sesuai dengan task dan tipe pengguna pada content management system program studi Universitas Dhyana Pura.

Kata kunci : Universitas Dhyana Pura, Content Managemen System, Task Centered System Design, Black box.
\end{abstract}




\section{PENDAHULUAN}

Universitas Dhyana Pura adalah salah satu universitas yang ada di Bali yang memiliki 2 fakultas dan 14 program studi. Universitas Dhyana Pura terletak di Kabupaten Badung tepatnya di Banjar Tegal Jaya, Dalung, Kuta Utara. Pada saat ini Universitas Dhyana Pura sendiri telah mempunyai media website namun dalam perkembangannya ada beberapa bagian yang perlu dikembangkan lagi supaya diperoleh website yang lebih dinamis, menarik dan mampu memberikan informasi yang dibutuhkan pengunjung website. Dan Universitas Dhyana Pura juga belum memiliki standardisasi content management system untuk system informasi program studi. Sehingga system informasi dari setiap program studi berbeda satu sama lain karena belum adanya standardisasi content management system. Oleh karena itu dibutuhkan content management system untuk memudahkan penyajikan informasi tentang Universitas Dhyana Pura kepada masyarakat dan supaya setiap program studi mempunyai standardisasi dalam pembuatan website program studi di Universitas Dhyana Pura.

Perkembangan dunia sistem informasi pada saat ini sudah sedemikian pesat dan merambah ke berbagai sisi kehidupan manusia. Sejak dikenalnya internet sebagai media informasi yang dapat diakses secara umum, aplikasi web menjadi semakin diminati. Website adalah salah satu contoh dari penggunaan internet yang sudah banyak digunakan baik di sekolah, instansi pemerintah, perusahaan, maupun komunitas untuk penyebarluasan informasi. Demikian pula dengan website program studi suatu perguruan tinggi. Website program studi telah menjadi salah satu kebutuhan untuk para mahasiswa, dosen, serta pengguna lainnya secara umum yang ingin mengetahui segala sesuatu tentang program studitersebut. Untuk membuat sebuah website biasanya dibutuhkan kemampuan dan pemahaman terkait pemrograman website sehingga diperlukan sebuah aplikasi yang dapat mempermudah pembuatan website itu sendiri. Aplikasi tersebut dikenal dengan istilah Content Management System (CMS). CMS menawarkan kemampuan untuk mengelola konten website tanpa harus mempunyai pengetahuan pemrograman website. CMS dirancang untuk memberikan kemudahan dalam mengelola konten website sesuai dengan keinginan pengguna CMS. Tanpa adanya content management system menggunakan metode task centered system design sebuah website dalam pengelolaan konten akan memerlukan waktu yang banyak dan seseorang yang akan mengelola konten websiste harus memiliki kemampuan dan pengetahuan pemrograman website.

Berdasarkan uraian diatas terlihat bahwa penggunaan teknologi informasi berbasis komputer akan sangat membantu dalam proses penyelesaian masalah, maka penulis tertarik untuk merancang content management system program studi Universitas Dhyana Pura menggunakan metode TCSD untuk memudahkan penyajikan informasi tentang program studi yang ada di Universitas Dhyana Pura kepada masyarakat luas.

\section{TINJAUAN PUSTAKA \\ Pengertian Sistem Informasi}

Telah diketahui bahwa informasi merupakan hal yang sangat penting bagi manajemen di dalam pengambilan keputusan. Informasi dapat diperoleh dari sistem informasi (information system) atau disebut juga dengan processing sistem atau information processing system atau information-generating system.

Sistem informasi dapat didefinisikan sebagai berikut sistem informasi adalah suatu sistem di dalam suatu organisasi yang mempertemukan kebutuhan pengolahan transaksi, mendukung operasi, bersifat managerial dan kegiatan strategi dari suatu organisasi dan menyediakan pihak luar tertentu dengan laporanlaporan yang diperlukan.

\section{Task Centered System Design (TCSD)}

Merupakan metode dalam Human Computer Interaction (HCI) yang digunakan untuk mengidentifikasi kebutuhan user dan kebutuhan task (Lewis \& Rieman, 2002). Hasil identifikasi digunakan sebagai dasar perbaikan interface yang didukung dengan observasi langsung pada user. Pengembangan perancangan content management system prodi Universitas Dhyana Pura berfokus pada penambahan content serta tampilan informasi yang disajikan. Metode TCSD meliputi 4 tahap, yaitu : identification, User-Centered 
Requirements Analysis, design as scenario dan walkthrough evaluate.

\section{Identifikasi (Identification)}

Pada tahap pertama tugas berpusat pada pengidentifikasi masalah dari pengguna dari sistem dan mengartikulasikan tugas-tugas yang realistis contoh yang akan mereka lakukan. Tujuan adalah untuk menghasilkan gambaran pengidentifikasian masalah pengguna dan tugas yang memberikan cakupan yang realistis akan menggunakan sistem untuk melakukan jenis tugas apa. Untuk mencapai tujuan ini, anda harus terlebih dahulu menemukan apa tugas-tugas atau permasalahan pengguna, kemudian menulis ini sebagai deskripsi tugas, dan akhirnya memvalidasi deskripsi untuk memastikan mereka mewakili realitas.

\section{User-Centered Requirements Analysis}

Tahap berikutnya dalam TCSD adalah menganalisis permasalahan yang ada serta untuk memutuskan apakah hasil dari analisis akan disertakan atau dikecualikan dari desain anda. Daftar ini akan menjadi user dasar anda berpusat analisis persyaratan desain sistem anda. Tahap penelitian atas sistem yang telah ada dengan tujuan untuk merancang sistem yang baru atau diperbaharui. Tahap ini merupakan tahap krisis dan sangat penting karena akan dapat menentukan berhasil tidaknya sistem yang akan dibangun atau dikembangkan.

\section{Desain melalui Skenario (Design as Scenario)}

Tahap yang menentukan desain sistem proses dan data yang diperlukan oleh sistem baru dan mengembangkan desain untuk menyesuaikan pengguna dan tugas tertentu. Membuat desain secara simulasi, dimana desain al-

\section{Web Server}

Web server adalah merupakan software yang memberikan layanan data yang berfungsi menerima permintaan HTTP atau HTTPS dari klien yang dikenal dengan browser web dan mengirimkan kembali hasilnya dalam bentuk halaman-halaman web yang umumnya berbentuk dokumen HTML. ternatif tersebut dikembalikan pada user sehingga diperoleh satu alternatif desain yang sesuai dengan kebutuhan user.

\section{Walkthrough Evaluate}

Pada tahap ini melakukan evaluasi akhir terhadap desain system kemudian dimana desain sistem dibentuk dan dibangun menjadi suatu kode (program) yang siap untuk dioperasikan.

\section{SDLC (System Development Life Cycle)}

SDLC adalah proses pengembangan atau mengubah suatu sistem perangkat lunak dengan menggunakan model-model dan metodologi yang digunakan untuk mengembangkan sistem-sistem perangkat lunak sebelumnya (Rosa A.S \& M. Shalahudin, 2013).

\section{Sistem Manajemen Konten (CMS)}

Sistem manajemen konten atau yang sering disebut CMS yang merupakan singkatan dari Content Management System yaitu sebuah aplikasi yang dikembangkan untuk memudahkan mengelola website (updating, maintenance) sehingga bisa dilakukan dengan efektif, efisien untuk mengelola website agar diupdate tiap hari, jam bahkan tiap detik maka perlu rancangan website yangdinamis.

CMS merupakan sebuah sistem yang memberikan kemudahan kepada para penggunanya dalam mengelola dan mengadakan perubahan isi sebuah website dinamis tanpa sebelumnya dibekali pengetahuan tentang hal-hal yang bersifat teknis. Dengan demikian, setiap orang, penulis maupun editor, setiap saat dapat menggunakannya secara leluasa untuk membuat, menghapus, atau bahkan memperbaharui isi website tanpa campur tangan langsunng dari pihakwebmaster.

\section{Web Browser}

Web Browser adalah suatu program yang digunakan untuk menjelajahi dunia internet atau untuk mencari informasi tentang suatu halaman web yang tersimpan di komputer. 


\section{Database MySQL}

Database adalah sekumpulan data store (bisa dalam jumlah yang sangat besar) yang tersimpan dalam magnetic disk, oftical disk, magnetic drum, atau media penyimpanan sekunder lainya.

\section{HTML}

HTML (Hyper Text Markup Language) adalah bahasa yang digunakan pada dokumen web sebagai bahasa untuk pertukaran dokumen web.

\section{PHP}

PHP adalah pemograman (interpreter) adalah proses penerjemahan baris sumber menjadi kode mesin yang dimengerti komputer secara langsung pada saat baris kode dijalankan.

\section{Apache}

Apache adalah web server yang dapat dijalankan dibanyak sistem operasi (Unix, BSD, Linux, Microsoft windows dan Novell Netware serta Platfrom lainnya) yang berguna untuk memfungsikan situs web.

\section{CSS}

CSS (Cascading Style Sheet) adalah suatu teknologi yang digunakan untuk mempermudah pembuatan suatu tampilan sebuah website

\section{Data Flow Diagram (DFD)}

Data flow diagram (DFD) merupakan alat yang di gunakan untuk menggambarkan suatu sistem yang telah ada atau sistem baru yang akan di kembangkan secara logika tanpa mempertimbangkan lingkungan fisik dimana data tersebut mengalir ataupun lingkungan disimpan

\section{Flowchart}

Bagan alir program (program flowchart) merupakan bagan alir yang mirip dengan bagan alir sistem, yaitu untuk menggambarkan prosedur di dalam sistem.

\section{ERD ( Entity Relationship Diagram )}

Entity Relationship Diagram (ERD) merupakan suatu model data yang dikembang- kan berdasarkan objek(Sutanta, 2011). Entity Relationship Diagram (ERD) digunakan untuk menjelaskan hubungan antar data dalam basis data kepada pengguna secara logis.

\section{Black Box Testing}

Pengujian menggunakan sekumpulan aktifitas validasi, dengan pendekatan black box testing. Menurut Shalahuddin dan Rosa (2011), black box testing adalah menguji perangkat lunak dari segi spesifikasi fungsional tanpa menguji desain dan kode program.

\section{METODELOGI PENELITIAN \\ Studi Kepustakaan}

Dalam menunjang penelitian akan dilakukan studi pustaka dengan mempelajari beberapa buku teks, jurnal, dan karya ilmiah lainnya yang menunjang beberapa penelitian tentang perancangan dan inplementasi aplikasi sistem pakar untuk kerusakan speaker aktif dengan metode backward chaining.

\section{Analisis dan Perancangan Sistem}

Tahap ini dilakukan perancangan disain sistem yang meliputi : pengumpulan data, analisis dan proses perancangan sistem, dan disain antar muka. Pengumpulan data, yaitu mengadakan pembuatan dokumen yang akan menunjang websiste yang akan dibuat agar nantinya sistem bisa dikembangkan lebih lanjut. Dalam tahap ini adalah melakukan pengumpulan dan pengolahan data mengenai content management system meenggunakan metode studi literature dan observasi.

\section{Desain}

Setelah dilakukan analisis dari web yang akan dikembangkan, maka langkah selanjutnya adalah membuat desain atau rancangan sistem. Yang termasuk di dalam tahap ini adalah penggambaran arus data yang mengalir dalam system menggunakan DFD (data flow diagram) yang di bagi dalam beberapa bagian, dimulai dari diagram konteks (context diagram) dan penggambaran dari level 0 sehingga level $\mathrm{n}$. Perangkat lunak yang digunakan dalam penggambaran arus data ini adalah Microsoft Visio 2010.

\section{Task Centered System Design (TCSD) Identification}

1. Alur pengelolaan oleh super admin. 
Saat akan melakukan pengelolaan seorang admin super harus melakukan login terlebih dahulu. Baru bisa melakukan pengelolaan CMS program studi Universitas Dhyana. Dan kemudian sigout.

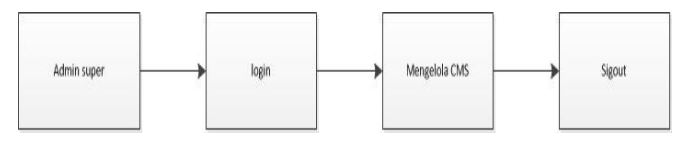

Gambar 1 Alur Pengelolaan oleh super admin

2. Alur pengelolaan program studi Saat akan melakukan pengelolaan prodi seorang admin prodi harus melakukan login terlebih dahulu. Baru bisa melakukan pengelolaan program studi dan terbatas hanya dapat mengelola 1 prodi, tidak dapat mengelola prodi lainnya. Dan kemudian Sigout.

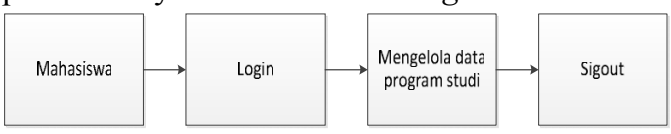

Gambar 2 Alur Pengelolaan Data Prodi

3. Alur pengelolaan kegiatan/berita mahasiswa

Saat akan melakukan pengelolaan kegiatan/berita tentang mahasiswa, mahasiswa yang mempunyai akun atau yang diberikan hak akses harus melakukan login terlebih dahulu. Agar bisa melakukan pengelolaan kegiatan/berita mahasiswa. Dan kemudian sigout.

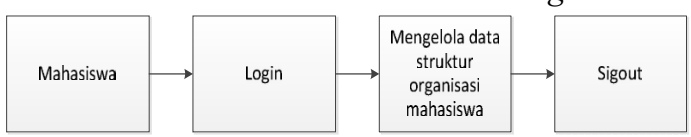

Gambar 3 Alur Pengelolaan Struktur Organisasi Mahasiswa

\section{User-Centered Requirement Analysis}

Tahap analisis ini merupakan tahap kedua dari tahapan TCSD. Sistem yang berjalan pada program studi Universitas Dhyana Pura saat ini tidak mempunyai standardisasi antara prodi satu dengan prodi yang lainnya artinya informasi yang terdapat pada setiap prodi berbeda-beda dan tidak lengkap.

\section{Design as Scenario}

Scenario digunakan untuk merepresentasikan sebuah interaksi antara aktor dengan sistem, aktor yang dimaksudkan adalah user.
Scenario ini menyatakan urutan pesan dan juga tindakan tunggal dari sistem.

\section{Walk-Through Evaluation}

Pada tahapan ini semua hasil dari design as scenario akan dikodekan kedalam bahasa pemrograman menggunakan bahasa scripting PHP dan database MySQL, selanjutnya akan dilakukan evaluasi terhadap desain apakah sudah sesuai dengan kebutuhan task dan kebutuhan user.

\section{Flowchart}

Flowchart merupakan suatu bagan dengan simbol-simbol tertentu yang menggambarkan urutan proses secara mendetail dan hubungan antara suatu proses (interaksi) dengan proses lainnya dalam suatu program. Berikut gambaran urutan proses perancangan content managemen system program studiUniversitas Dhyana Pura menggunakan Metode TCSD (Task Centered System Design) :

\section{Flowchart User (Super Admin)}

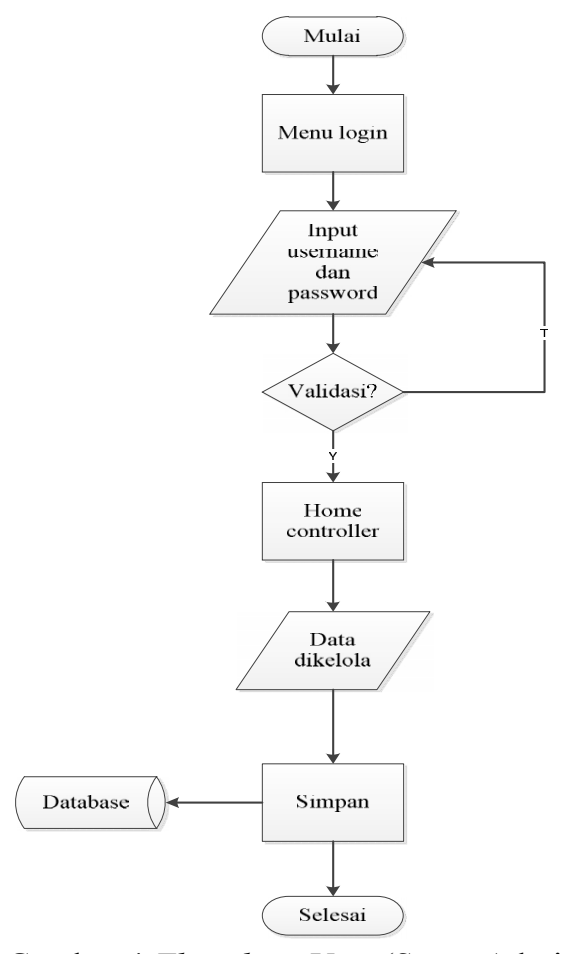

Gambar 4 Flowchart User (Super Admin) 


\section{Flowchart Prodi User (Admin Prodi)}

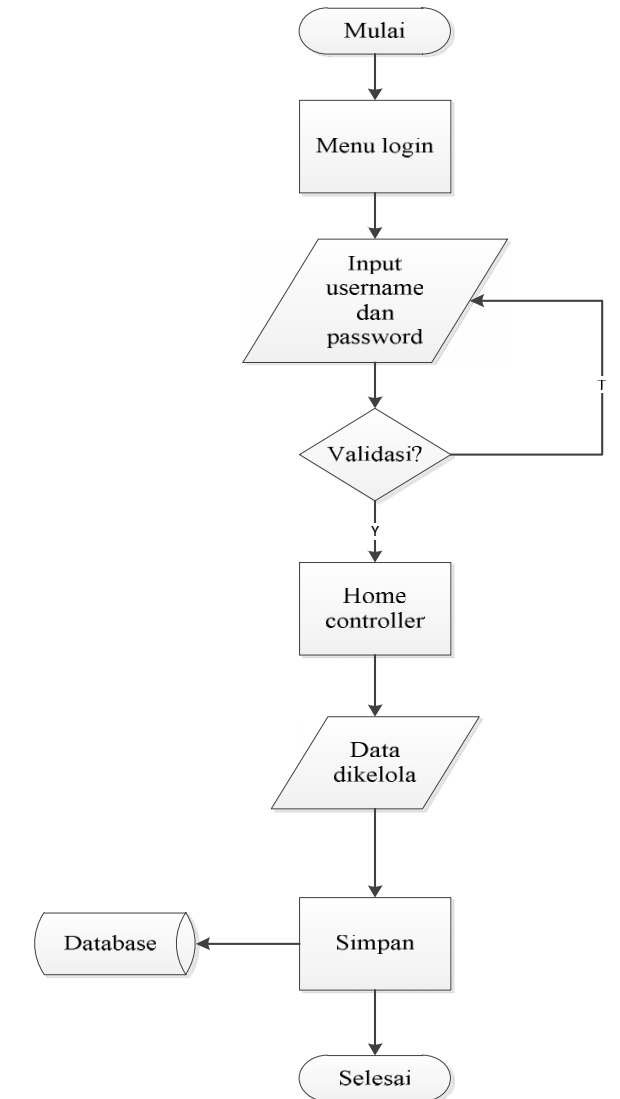

Gambar 5 Flowchart Prodi User (Admin Prodi)

\section{Flowchart Prodi User (Mahasiswa)}

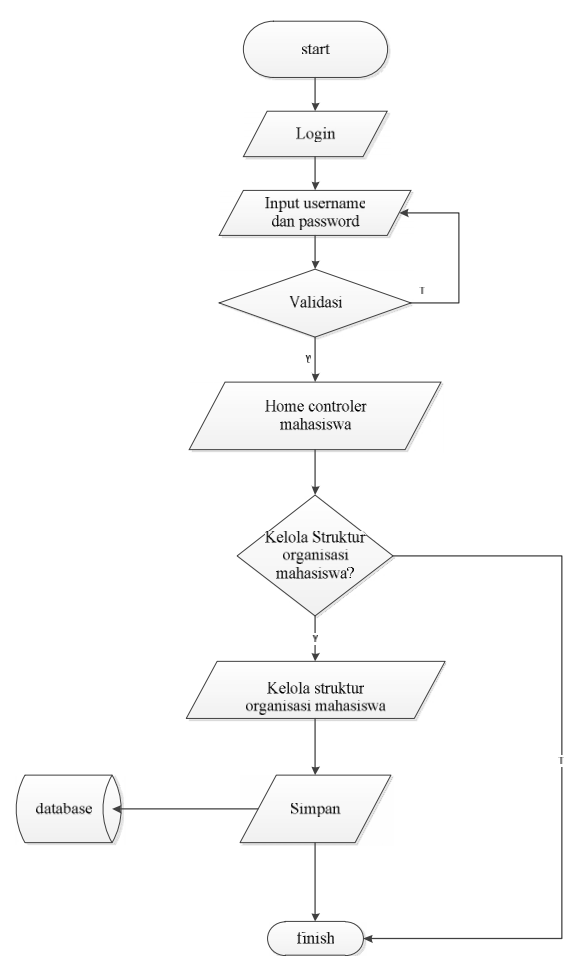

Gambar 6 Flowchart Prodi User (Mahasiswa)

\section{Data Flow Diagram (DFD)}

Data Flow Diagram digunakan untuk menggambarkan system yang ditekankan untuk melihat bagaimana proses-proses yang terjadi dari system yang diterapkan termasuk juga proses-proses manual yang ada. Dengan menggunakan DFD proses system dapat dijelaskan kepada pemakai system sehingga memperoleh kejelasan dalam penerapan aplikasi tersebut.

Berikut merupakan DFD dari Perancangan Content Management System Universitas Dhyana Pura yang bertujuan untuk memperoleh gambaran mengenai system yang nantinya akan diterapkan :

Diagram Konteks Perancangan Content Managemen System Prodi Universitas Dhyana Pura

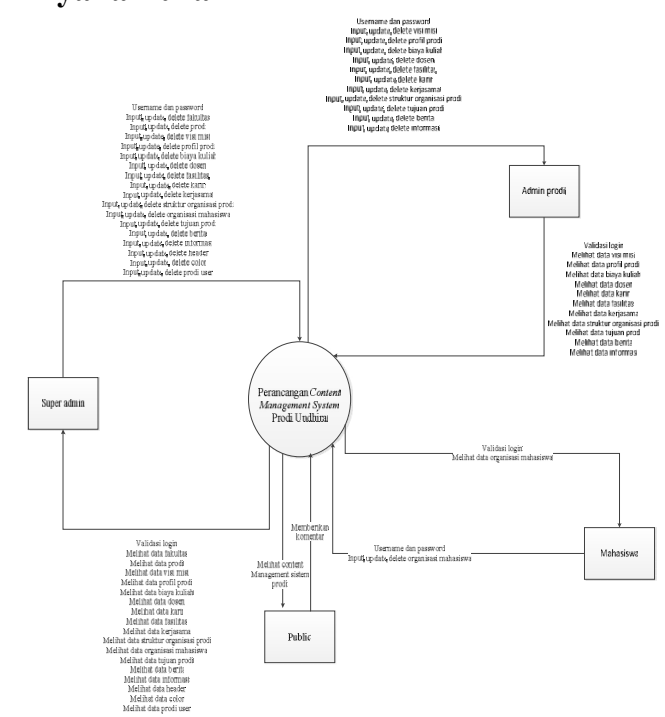

Gambar 7 Diagram Konteks Perancangan Content Management System Prodi Undhira

DFD Level 0 Perancangan Content Management System Prodi Universitas Dhyana Pura

Berikut adalah gambar DFD Level 0 Perancagan Content Management System Prodi Universitas Dhyana Pura : 


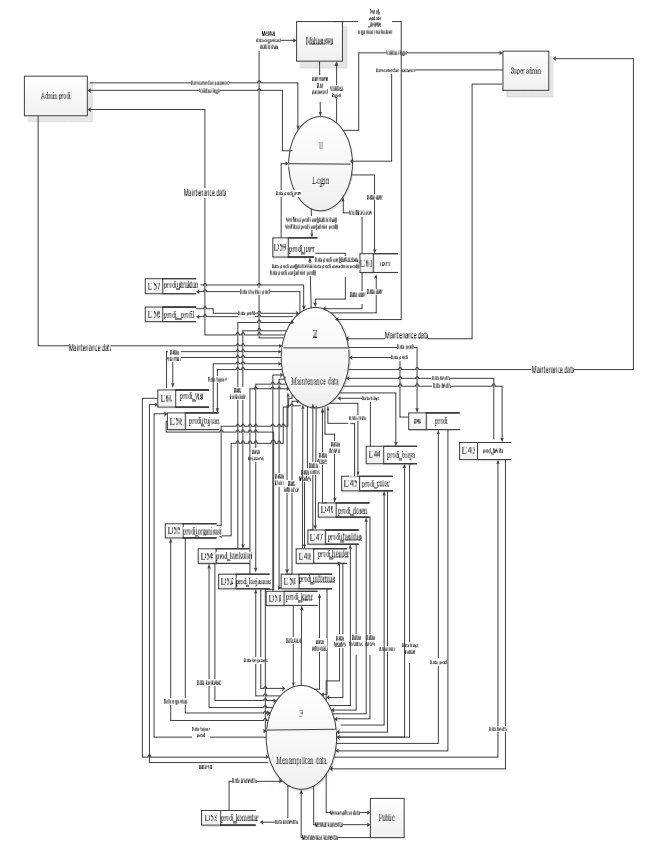

Gambar 8 DFD Level 0 Perancangan Content Management System Prodi Undhira

\section{DFD Level 1 Perancangan Content Management System Prodi Universitas Dhyana Pura}

Berikut adalah gambar DFD Level 1 Perancangan Content Management System Prodi Universitas Dhyana Pura.

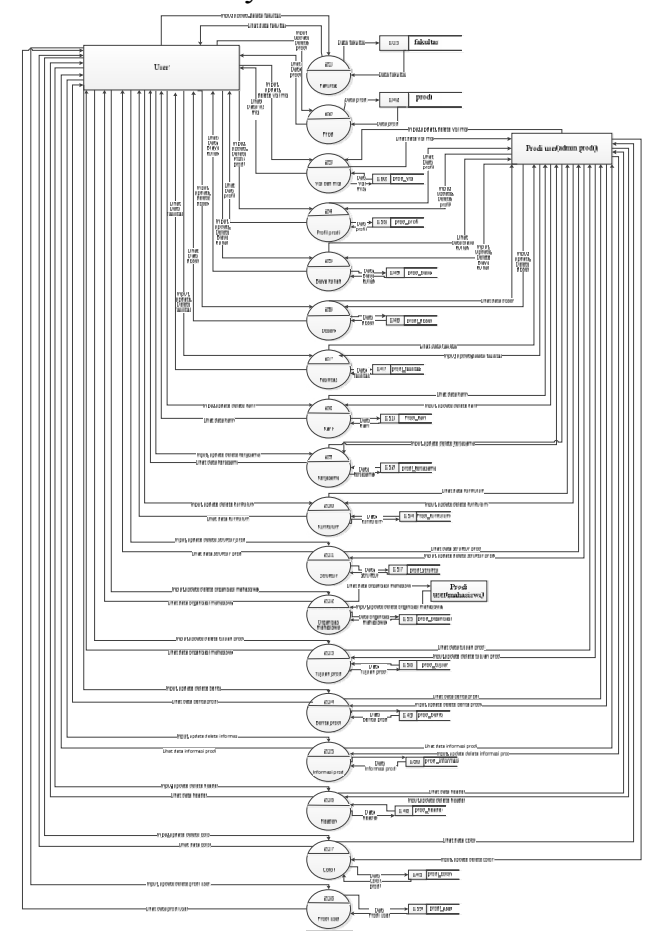

Gambar 9 DFD Level 1 Perancangan Content Management System Prodi Undhira

\section{Entity Relationship Diagram (ERD)}

Entity Relationship Diagram (ERD) merupakan sebuah model konseptual yang menggambarkan hubungan antara entitas dan penyimpanan data. Dalam Perancangan Content Management System ini, ERD yang akan digunakan adalah sebagai berikut :

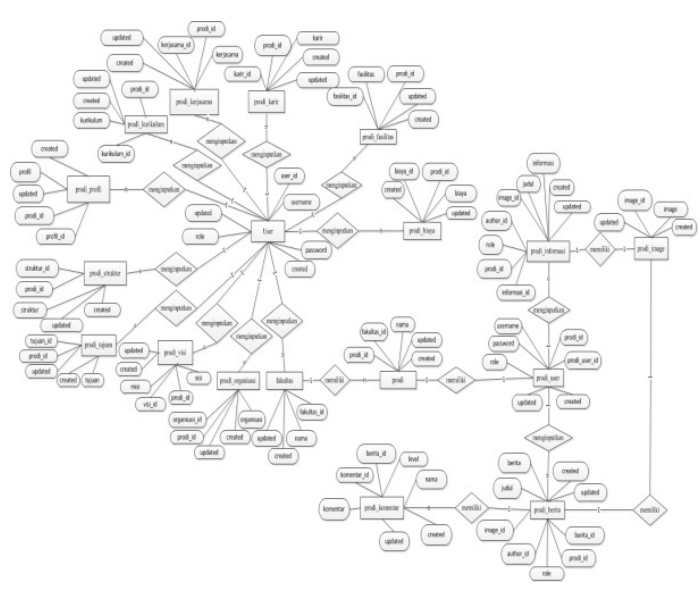

Gambar 10 Entity Relationship Diagram

(ERD) Perancangan Content Management System Prodi Undhira

\section{Perancangan Database}

Adapun perancangan struktur database dilakukan dengan menggunakan MYSQL.

\section{HASIL DAN PEMBAHASAN}

Implementasi Sistem

Tahap implementasi sistem merupakan tahap penerapan system agar dapat dioperasikan secara optimal sesuai dengan kebutuhan. Implemetasi antarmuka yang dibuat pada tahap perancangan, diimplementasikan menjadi bentuk halaman web yang dibangun dengan menggunakan perangkat lunak implementasi program.

\section{Implementasi Pembuatan Pengguna}

Pengguna atau user dimaksudkan untuk mengetahui siapa saja pengguna yang terlibat dalam sistem informasi ini. Sistem yang sedang berjalan melibatkan 3 pengguna, yaitu : admin super, admin prodi dan mahasiswa.

\section{Implementasi Antar Muka}

Implementasi antarmuka dilakukan dengan setiap halaman program yang 
dibuat dan pengkodeannya dalam bentuk file program. Berikut ini adalah implementasi antarmuka untuk Admin Super Admin Prodi dan mahasiswa.

\section{Tampilan Form Admin Super}

1. Tampilan Form Login Super Admin

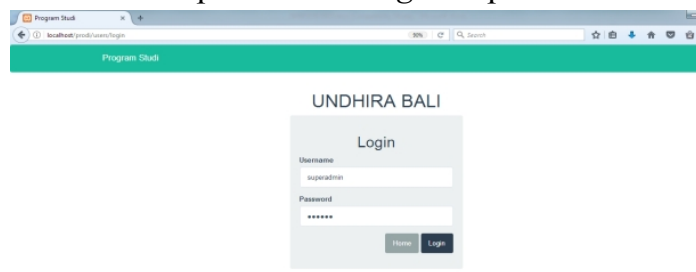

Gambar 11 Tampilan Form Login Super

$$
\text { Admin }
$$

2. Tampilan From Controller Super Admin

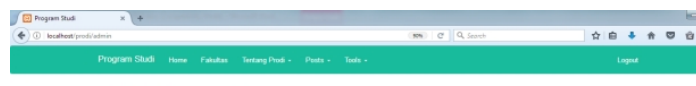

DASHBOARD ADMIN

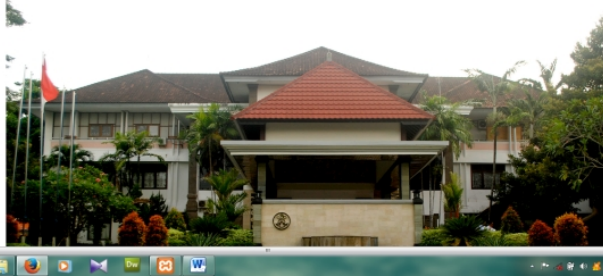

Gambar 12 Tampilan Form Controller Super Admin

3. Tampilan Form Menu data Prodi

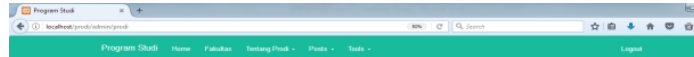
Program Studi $+\sin x$

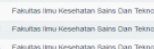

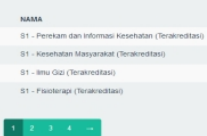

1. . .

Gambar 13 Tampilan Form Menu data Prodi
4. Tampilan Form Menu data Visi dan Misi Prodi

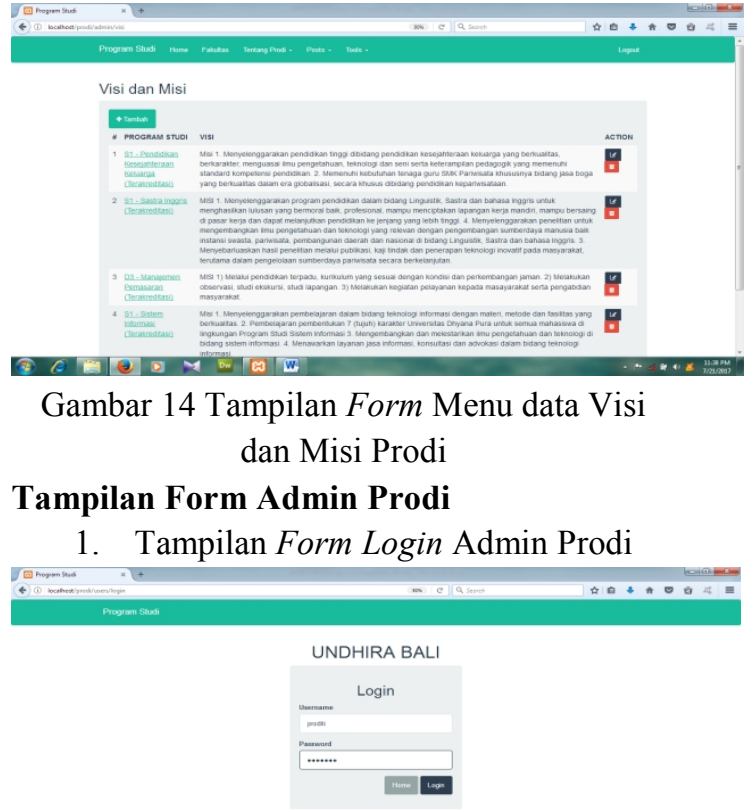

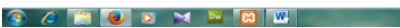

Gambar 15 Tampilan Form Login Admin Prodi

2. Tampilan Form Controller Admin Prodi

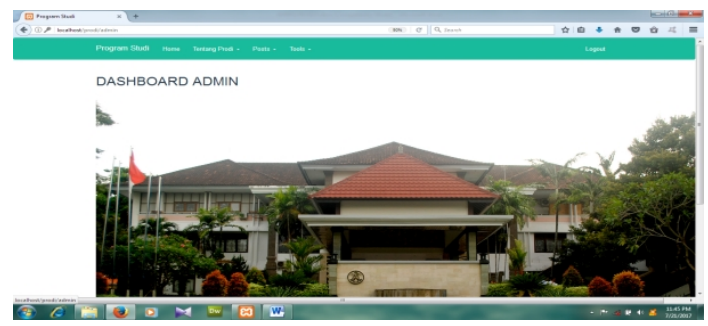

Gambar 16 Tampilan Form ControllerAdmin

Prodi

\section{Tampilan Form Mahasiswa}

1. Tampilan Form Login Mahasiswa

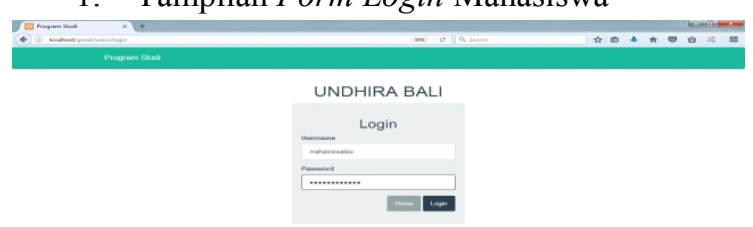

Gambar 17 Tampilan Form Login Mahasiswa 
2. Tampilan Form Controller Mahasiswa

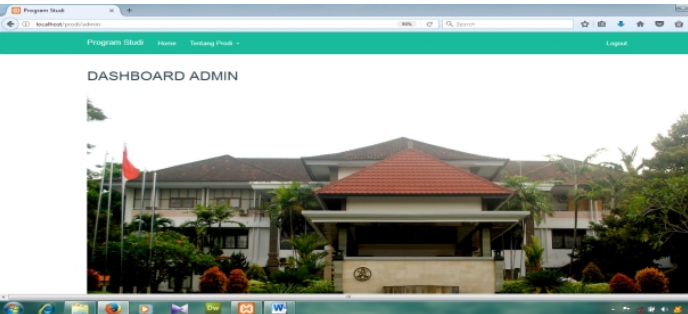

Gambar 18 Tampilan Form Controller Mahasiswa

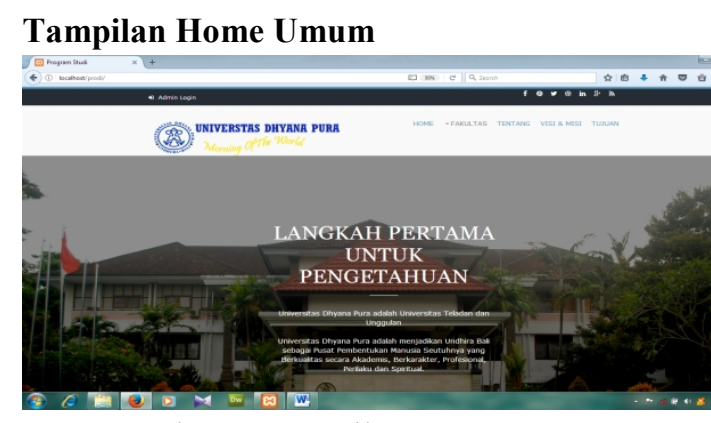

Gambar 19 Tampilan Home Umum

Tampilan Program Studi Teknik Informatika

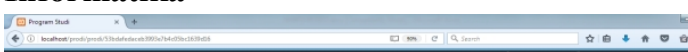

(C.R.

UNIVERSTTAS DHYANA PURA

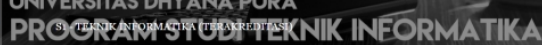

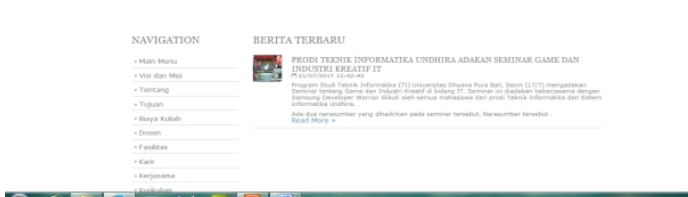

Gambar 20 Tampilan Program Studi Teknik Informatika

Tampilan Program Studi Manajemen
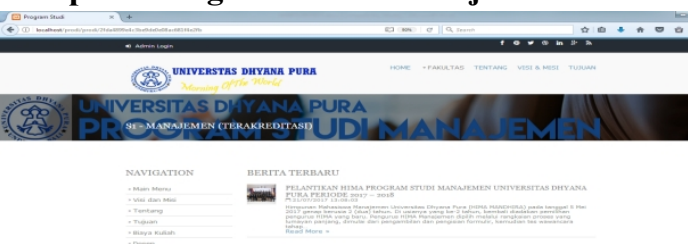

Gambar 21 Tampilan Program Studi Manajemen

\section{Pengujian Sistem}

Pengujian rancangan content management system ini menggunakan metode pengujian Black Box. Pengujian black box berfokus pada persyaratan fungsional perangkat lunak.

\section{Rencana Pengujian}

Rencana pengujian selengkapnya dapat dilihat pada tabel-tabel berikut :

Tabel 1 Rencana Pengujian

\begin{tabular}{|c|c|c|}
\hline Kelas Uji & Butir uji & $\begin{array}{c}\text { Jenis } \\
\text { Pengujian }\end{array}$ \\
\hline \multirow{2}{*}{ Login } & $\begin{array}{l}\text { Verifikasi } \\
\text { Username }\end{array}$ & Black box \\
\hline & $\begin{array}{l}\text { Verifikasi } \\
\text { password }\end{array}$ & Black box \\
\hline \multirow[t]{5}{*}{$\begin{array}{c}\text { Pengolahan } \\
\text { data prodi }\end{array}$} & $\begin{array}{c}\text { Tambah data } \\
\text { prodi }\end{array}$ & Black box \\
\hline & $\begin{array}{c}\text { Edit data } \\
\text { prodi }\end{array}$ & Black box \\
\hline & $\begin{array}{l}\text { Hapus data } \\
\text { prodi }\end{array}$ & Black box \\
\hline & $\begin{array}{c}\text { Simpan data } \\
\text { prodi }\end{array}$ & Black box \\
\hline & $\begin{array}{l}\text { Batal data } \\
\text { prodi }\end{array}$ & Black box \\
\hline \multirow[t]{5}{*}{$\begin{array}{c}\text { Pengolahan } \\
\text { data visi dan } \\
\text { misi prodi }\end{array}$} & $\begin{array}{c}\text { Tambah data } \\
\text { visi dan misi } \\
\text { prodi }\end{array}$ & Black box \\
\hline & $\begin{array}{c}\text { Edit data } \\
\text { admin visi } \\
\text { dan misi } \\
\text { prodi }\end{array}$ & Black box \\
\hline & $\begin{array}{c}\text { Hapus data } \\
\text { visi dan misi } \\
\text { prodi }\end{array}$ & Black box \\
\hline & $\begin{array}{c}\text { Simpan data } \\
\text { visi dan misi } \\
\text { prodi }\end{array}$ & Black box \\
\hline & $\begin{array}{c}\text { Batal data } \\
\text { visi dan misi } \\
\text { prodi }\end{array}$ & Black box \\
\hline \multirow[t]{5}{*}{$\begin{array}{c}\text { Pengolahan } \\
\text { data profil } \\
\text { prodi }\end{array}$} & $\begin{array}{l}\text { Tambah data } \\
\text { profil prodi }\end{array}$ & Black box \\
\hline & $\begin{array}{l}\text { Edit data } \\
\text { profil prodi }\end{array}$ & Black box \\
\hline & $\begin{array}{l}\text { Hapus data } \\
\text { profil prodi }\end{array}$ & Black box \\
\hline & $\begin{array}{l}\text { Simpan data } \\
\text { profil prodi }\end{array}$ & Black box \\
\hline & $\begin{array}{l}\text { Batal data } \\
\text { profil prodi }\end{array}$ & Black box \\
\hline
\end{tabular}




\section{Kasus dan Hasil Pengujian}

Berdasarkan rencana pengujian yang telah disusun, maka dapat dilakukan pengujian sebagai berikut.

\section{Login User}

Berikut ini adalah tabel pengujian login user untuk verifikasi username dan password:

Tabel 2 Pengujian Verifikasi Data Login User

\begin{tabular}{|c|c|}
\hline \multicolumn{2}{|c|}{ Kasus Dan Hasil Uji (Data Normal) } \\
\hline $\begin{array}{c}\text { Data } \\
\text { masukkan }\end{array}$ & $\begin{array}{l}\text { Username : superadmin dan } \\
\text { password : superadmin } \\
\text { Username : adminti dan } \\
\text { password : adminti } \\
\text { Username : mahasiswati } \\
\text { dan mahasiswati }\end{array}$ \\
\hline $\begin{array}{c}\text { Yang } \\
\text { diharapkan }\end{array}$ & $\begin{array}{l}\text { Username dan password } \\
\text { yang dimasukkan benar } \\
\text { sehingga user dapan masuk } \\
\text { ke dalam menu controller. }\end{array}$ \\
\hline Pengamatan & $\begin{array}{l}\text { Username dan password } \\
\text { yang dimasukkan diterima }\end{array}$ \\
\hline Kesimpulan & Diterima \\
\hline \multicolumn{2}{|c|}{ Kasus Dan Hasil Uji (Data Salah) } \\
\hline $\begin{array}{c}\text { Data } \\
\text { masukkan }\end{array}$ & $\begin{array}{l}\text { Username : superadmin dan } \\
\text { password : } 12345 \\
\text { Username : adminti dan } \\
\text { password : } 12345 \\
\text { Username : mahasiswati } \\
\text { dan password: mahasiswa }\end{array}$ \\
\hline $\begin{array}{c}\text { Yang } \\
\text { diharapkan }\end{array}$ & $\begin{array}{l}\text { Setelah klik tombol login } \\
\text { maka kolom user dan } \\
\text { password akan kembali } \\
\text { kosong }\end{array}$ \\
\hline Pengamatan & $\begin{array}{l}\text { Kolom user dan password } \\
\text { kosong }\end{array}$ \\
\hline Kesimpulan & Diterima \\
\hline \multicolumn{2}{|c|}{ Kasus Dan Hasil Uji (Data Kosong) } \\
\hline $\begin{array}{c}\text { Data } \\
\text { masukkan }\end{array}$ & $\begin{array}{l}\text { Username : dikosongkan } \\
\text { dan password:dikosongkan } \\
\text { Username : dikosongkan } \\
\text { dan password:dikosongkan } \\
\text { Username : dikosongkan } \\
\text { dan password:dikosongkan }\end{array}$ \\
\hline $\begin{array}{c}\text { Yang } \\
\text { diharapkan }\end{array}$ & $\begin{array}{l}\text { Muncul pesan error, the } \\
\text { username and the } \\
\text { password field is required }\end{array}$ \\
\hline Pengamatan & $\begin{array}{l}\text { Muncul pesan error, the } \\
\text { username }\end{array}$ \\
\hline
\end{tabular}

\begin{tabular}{|l|l|}
\hline & password field is required \\
\hline Kesimpulan & Diterima \\
\hline
\end{tabular}

2. Pengolahan Data Prodi

Tabel 3 Pengujian Pengolahan Data Prodi

\begin{tabular}{|c|c|}
\hline \multicolumn{2}{|c|}{ Kasus Dan Hasil Uji (Data Normal) } \\
\hline $\begin{array}{c}\text { Data } \\
\text { masukkan }\end{array}$ & Data program studi. \\
\hline $\begin{array}{c}\text { Yang } \\
\text { diharapkan }\end{array}$ & $\begin{array}{l}\text { Klik tambah program studi } \\
\text { maka akan muncul } \\
\text { pengolahan data program } \\
\text { studi, isi data program studi } \\
\text { dan kemudian klik simpan. }\end{array}$ \\
\hline Pengamatan & Data berhasil tersimpan \\
\hline Kesimpulan & Diterima \\
\hline \multicolumn{2}{|c|}{ Kasus Dan Hasil Uji (Data kosong) } \\
\hline $\begin{array}{c}\text { Data } \\
\text { masukkan }\end{array}$ & $\begin{array}{l}\text { Data program studi } \\
\text { dikosongkan. }\end{array}$ \\
\hline $\begin{array}{c}\text { Yang } \\
\text { diharapkan }\end{array}$ & $\begin{array}{l}\text { Klik tambah program studi } \\
\text { maka akan muncul } \\
\text { pengolahan data program } \\
\text { studi, data program studi } \\
\text { dikosongkan. Klik simpan } \\
\text { muncul error, fakultas dan } \\
\text { prodi field is required. }\end{array}$ \\
\hline Pengamatan & $\begin{array}{l}\text { Saat klik simpan muncul } \\
\text { error, fakultas dan prodi } \\
\text { field is required. }\end{array}$ \\
\hline Kesimpulan & Diterima \\
\hline
\end{tabular}

\section{Pengolahan Data Visi dan Misi}

Tabel4 Pengujian Pengolahan Data Visi dan Misi

\begin{tabular}{|c|l|}
\hline \multicolumn{2}{|c|}{ Kasus Dan Hasil Uji (Data Normal) } \\
\hline $\begin{array}{c}\text { Data } \\
\text { masukkan }\end{array}$ & $\begin{array}{l}\text { Data visi dan misi Program } \\
\text { studi. }\end{array}$ \\
\hline $\begin{array}{c}\text { Yang } \\
\text { diharapkan }\end{array}$ & $\begin{array}{l}\text { Klik tambah visi dan misi } \\
\text { maka akan muncul } \\
\text { pengolahan data visi dan } \\
\text { misi prodi, isi data visi misi } \\
\text { dan kemudian klik simpan. }\end{array}$ \\
\hline Pengamatan & Data berhasil tersimpan \\
\hline Kesimpulan & Diterima \\
\hline $\begin{array}{c}\text { Kasus Dan Hasil Uji (Data kosong) } \\
\text { masukkan }\end{array}$ & $\begin{array}{l}\text { Data visi dan misi program } \\
\text { studi dikosongkan. }\end{array}$ \\
\hline $\begin{array}{l}\text { Yang } \\
\text { diharapkan }\end{array}$ & $\begin{array}{l}\text { Klik tambah visi dan misi } \\
\text { program studi maka akan } \\
\text { muncul pengolahan data }\end{array}$ \\
\hline
\end{tabular}




\begin{tabular}{|c|l|}
\hline & $\begin{array}{l}\text { program studi, data visi dan } \\
\text { misi dikosongkan. Klik } \\
\text { simpan akan muncul error, } \\
\text { the visi and misi field is } \\
\text { required. }\end{array}$ \\
\hline Pengamatan & $\begin{array}{l}\text { Saat klik simpan akan } \\
\text { muncul pesan error, the visi } \\
\text { and misi field is required. }\end{array}$ \\
\hline Kesimpulan & Diterima \\
\hline
\end{tabular}

4. Pengolahan Data Profil Prodi

Tabel5 Pengujian Pengolahan Data Profil Prodi

\begin{tabular}{|c|c|}
\hline \multicolumn{2}{|c|}{ Kasus Dan Hasil Uji (Data Normal) } \\
\hline $\begin{array}{c}\text { Data } \\
\text { masukkan }\end{array}$ & Data profil prodi. \\
\hline $\begin{array}{c}\text { Yang } \\
\text { diharapkan }\end{array}$ & $\begin{array}{l}\text { Klik tambah profil prodi } \\
\text { maka akan muncul } \\
\text { pengolahan data profil } \\
\text { prodi, isi data profil prodi } \\
\text { dan kemudian klik simpan. }\end{array}$ \\
\hline Pengamatan & Data berhasil tersimpan \\
\hline Kesimpulan & Diterima \\
\hline \multicolumn{2}{|c|}{ Kasus Dan Hasil Uji (Data kosong) } \\
\hline $\begin{array}{c}\text { Data } \\
\text { masukkan }\end{array}$ & $\begin{array}{l}\text { Data profil prodi } \\
\text { dikosongkan. }\end{array}$ \\
\hline $\begin{array}{c}\text { Yang } \\
\text { diharapkan }\end{array}$ & $\begin{array}{l}\text { Klik tambah profil prodi } \\
\text { maka akan muncul } \\
\text { pengolahan data profil } \\
\text { prodi, data profil prodi } \\
\text { dikosongkan. Klik simpan } \\
\text { akan muncul pesan error, } \\
\text { the profil field is required. }\end{array}$ \\
\hline Pengamatan & $\begin{array}{l}\text { Saat klik simpan akan } \\
\text { muncul pesan error, the } \\
\text { profil field is required. }\end{array}$ \\
\hline Kesimpulan & Diterima \\
\hline
\end{tabular}

\section{SIMPULAN}

Berdasarkan hasil dan pembahasan yang telah penulis lakukan, maka kesimpulan yang dapat diambil dari penelitian ini adalah sebagai berikut: :

Perancangan content management system program studi Universitas Dhyana Pura dibangun penggunaan tahap pengembangan sistem Task Centered system Design (TCSD) yang melalui 4 tahap, yaitu identification, usercentered requirements analysis, design as scenario, dan walkthrough evaluate. Berhasil dirancang dan diimplemetasikan.
Sehingga dari hasil pengujian tujuan dari pembuatan website ini telah tercapai dimana kebutuhan task pengguna telah sesuai dengan task dan tipe pengguna pada content management system program studi Universitas Dhyana Pura.

\section{DAFTAR PUSTAKA}

Adi, N. (2010). Rekayasa Perangkat Lunak Berbasis Objek dengan Metode USDP. Yogyakarta: Andi.

Agus, S., Ridho, T. S., \& Saluky. (2012). Membangun Aplikasi E-Library Untuk Panduan Skripsi. PT. Elex Media Komputindo.

Anhar. (2010). PHP \& MySql Secara Otodidak. Jakarta: PT TransMedia.

Astamal, R. (2006). Mastering Kode HTML. Surabaya.

Fatta, A. (2007). Analisis dan Perancangan Sistem Informasi. Yogyakarta: Andi.

Jogiyanto, H. (2012). Analisis \& Desain Sistem Informasi. Yogyakarta: Andi.

Jogiyanto, H. (2012). Sistem Teknologi Informasi. Yogyakarta: Andi.

Junaedi. (2011). Aplikasi Teknologi Informasi dalam Bidang Pendidikan.

Kurniawan, R. (2008). Membangun Situs dengan PHP untuk Orang Awam. Palembang: Maxsikom.

Kusrini. (2007). Strategi Perancangan dan Pengolahan Basis Data. Yogyakarta: Andi.

Latjamudin, A.-B. B. (2013). Analisis dan Desain Sistem Informasi. Jogjakarta: Graha Ilmu.

Laudon, K. C., \& Laudon, C. J. (2007). Sistem Informasi Manajemen. Jakarta: Salemba Empat.

Lewis, C., \& Rieman, J. (2002). Task-Centered User Interface Design. Colorado: Boulder.

Rosa A.S, \& M. Shalahudin. (2013). SDLC (System Development Life Cycle).

Sibero, A. F. (2012). Kitab Suci Web Programing. Jakarta : Mediakom.

Sutanta, E. (2011). Basis Data dalam Tinjauan Konseptua. Yogyakarta: Andi. 
324 Jurnal Teknologi Informasi dan Komputer, Volume 3, Nomor 1, Januari 2017

Sutarman. (2009). Buku Pengantar Teknologi Informasi. Jakarta: Bumi Aksara.

Lasminiasih, dkk. 2016. Perancangan Sistem

Informasi Kredit Mikro Mahasiswa

Berbasis Web.

Riga, Sari. Rafika dkk. 2014. Rancang Bangun

Content Management System

Untuk Aplikasi Website Program Studi.

Sidin, sidik. 2009. Studi Content Management System Dan Pembangunan Modul ELibrary. 